\title{
JUURNAL.RU
}

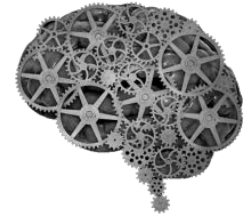

COMPANY GROUP "INTELLEKT"

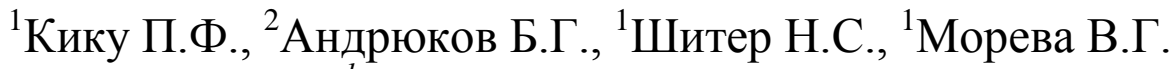 \\ ${ }^{1}$ Дальневосточный федеральный университет \\ ${ }^{2}$ Научно-исследовательский институт эпидемиологии и \\ микробиологии имени Г.П. Сомова \\ Владивосток, Россия
}

doi: 10.18411/lj2016-3-57

\section{Эколого-гигиеническая оценка распространения йоддефицитных заболеваний среди населения приморского региона}

Цель исследования - определить уровень распространения заболеваний щитовидной железы в зависимости от эколого-гигиенической ситуации. В работе использованы методы описательной статистики, эколого-гигиенической экспертизы. Установлено, что уровень тиреоидной патологии на территории Приморья наиболее высокий в районах, характеризующихся выраженным йоддефицитом (северо-западные геохимические зоны), где структура заболеваний щитовидной железы представлена преимущественно диффузным нетоксическим зобом. В прибрежных геохимических зонах, характеризующихся наибольшим содержанием йода, в структуре заболеваемости увеличиваются показатели аутоиммунных заболеваний.

В целях исследования потенциальной зависимости между экзогенными вредными факторами ОС природного и антропотехногенного генеза и формированием заболеваемости щитовидной железы (ЩЖ) среди населения региона в рамках комплексной эколого-гигиенической экспертизы в ПК был проведен популяционный эколого-гигиенический анализ заболеваемости населения региона. Принципиально важным моментом является выбор нозологических форм, которые могут служить маркерами экологического загрязнения и одновременно являются легкодоступными для наблюдения и 
учета. ЩЖ является органом внутренней секреции, очень чувствительным к малейшим изменениям параметров ОС. Все этапы осуществления ее функций могут подвергаться неблагоприятному влиянию техногенных факторов.

Анализ структуры заболеваемости населения ПК по IV классу МКБ-10 показал, что в зависимости от экологического напряжения территории проживания значение тиреоидной патологии возрастает с ухудшением условий проживания (рис. 1). Эпидемиологическая оценка ЙДЗ за последние 10-15 лет показала, что заболевания ЩЖ, ассоциированные с ЙД, стали самой распространенной эндокринной патологией, как у детей, так и у взрослых, опередив сахарный диабет. За последние годы в ПК среди всех категорий населения выросла патология эндокринной системы.

Заболеваемость подростков болезнями эндокринной системы увеличилась в 3,1 раза, тогда как заболеваемость детей - в 2,1 раза, взрослых - в 2,6 раза. Рост заболеваемости всех возрастных групп населения болезнями эндокринной системы согласуется информацией об экологической ситуации в стране [1].

Как показал санитарно-гигиенический анализ, геохимические особенности территории ПК характеризуются дисбалансом концентрации йода во в объектах OC в зависимости от биоклиматической зоны, повышенным содержанием в почве тяжелых металлов, пестицидов, которые создают зоны напряженной и критической экологической ситуации [2]. На территории Приморского края имеются геохимические провинции, располагающиеся в прибрежной и переходной биозонах, характеризующиеся дефицитом эссенциальных МЭ (никель, железо, германий, молибден, цинк, селен) и повышенным уровнем токсичных микроэлементов (стронций, никель, кадмий, свинец, мышьяк, олово). Содержание указанных ХЭ варьирует в разных биогеохимических зонах и подзонах ПК. Этот дисбаланс свидетельствует о многокомпонентности взаимоотношений микроэлементов друг с другом и влиянии их на тиреоидную систему. 


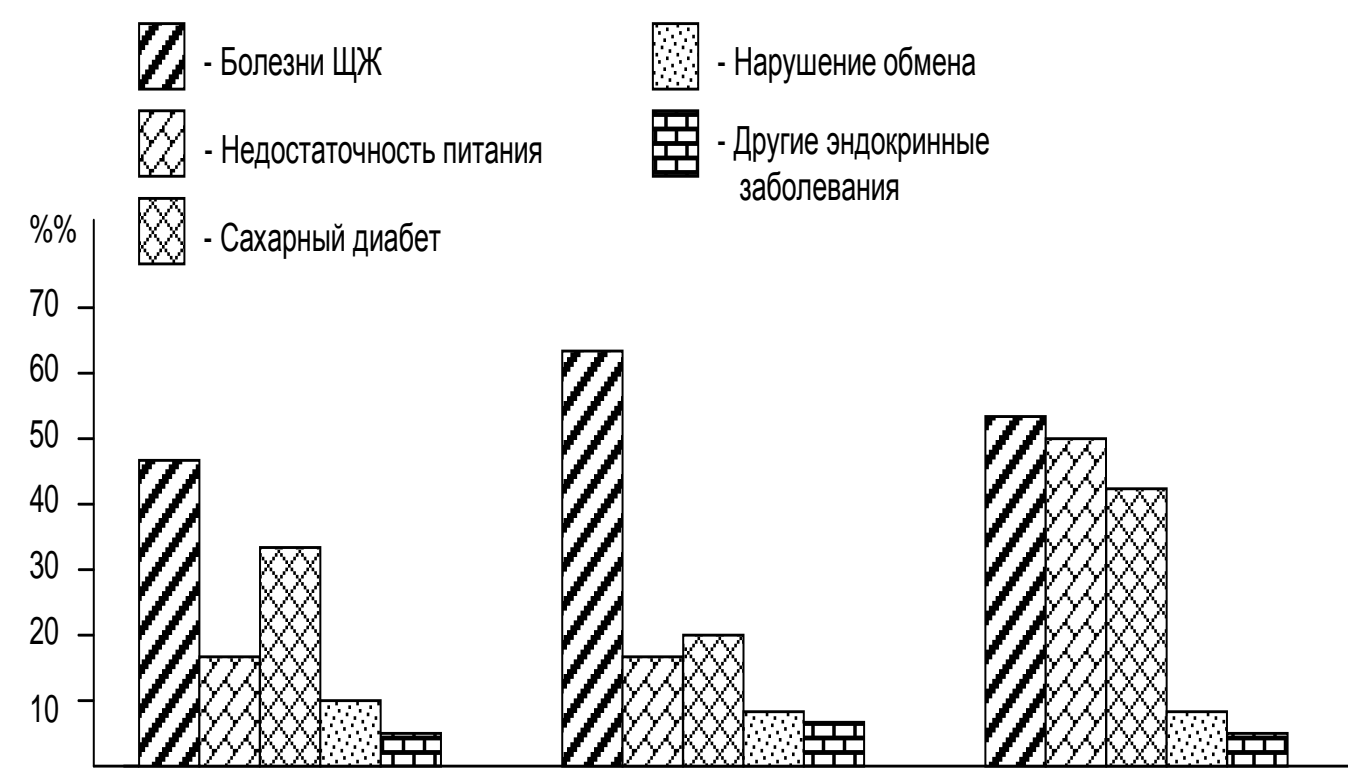

Удовлетворительная

Напряженная

Критическая

Зоны экологического Напряжения ПК

Рис. 1. Структура эндокринной патологии у населения ПК в зависимости от экологического напряжения территории проживания

Проведенная эколого-гигиеническая оценка распространения заболеваний ЩЖ среди населения ЩЖ, ассоциированных с ЙД, в связи с геохимической и экологической ситуацией показала, что за последние 10 лет в крае произошел значительный рост распространенности данной патологии во всех группах населения. Наименее благополучными территориями по тиреоидной патологии стали районы, характеризующиеся наибольшей химической загрязненностью ОС в опасных для здоровья концентрациях - Ханкайский, Тернейский, Михайловский, Пограничный, Октябрьский, г. Дальнегорск. При этом указанные территории по содержанию йода в объектах ОС занимают промежуточное положение, а в наиболее обедненных йодом районах (Пожарский, гг. Дальнереченск, Арсеньев, Лесозаводск) заболеваемость ЩЖ ниже среднего по краю уровня

Анализ закономерностей распространения ЙДЗ в регионе позволил выделить территории, где эта патология более распространена. Обращает на себя внимание, что распространение заболеваний ЩЖ не совпадает с 
йоддефицитными территориями и районами прибрежной зоны региона, наиболее благополучными в отношении содержания этого МЭ в объектах ОС (2396-4679 г/т). В северо-западных территориях края (наиболее обедненные йодом, 1850-2115 г/т) и юго-восточных районах, характеризующихся максимальным содержанием элемента уровень заболеваемости примерно на одном уровне. Эндемическими территориями по ЙДЗ в крае можно характеризовать зоны Приханковья, юга Приморья и северного морского побережья, наиболее неблагополучные в экологическом отношении районы.

Оценка уровня заболеваемости по модельным геохимическим точкам выявила, что распространение всей патологии ЩЖ связаны с типом геохимических провинций. Для Уссурийской зоны Лучегорского экологогеохимического района характерны высокие уровни синдрома ВГ у детей; у взрослых - тиреотоксикоза (гипертиреоза) и тиреоидита среди подростков. Это связано с высокими концентрациями в почве мышьяка, кадмия, никеля, значительно превышающими предельно допустимые значения. В ЮжноПриморской зоне Владивостокского эколого-геохимического узла отмечаются высокие уровни СГ у подростков, ДНЗ у детей, гипертиреоза у взрослых. В этих районах наблюдаются высокие концентрации мышьяка, цинка, свинца. СихотэАлинская зона Дальнегорского эколого-геохимического района характеризуется высокими уровнями ДНЗ у всех групп населения, МУЗ у детей и подростков, тиреотоксикоза у детей, что связано с высокими концентрациями свинца, мышьяка, цинка, кадмия, ртути.

Оценка распространения патологии ЩЖ у взрослых и подростков в зависимости от экологической ситуации и биоклиматической зоны с использованием коэффициента $\chi 2$ Пирсона показала, что имеются статистически достоверные различия в уровнях заболеваемости по различным нозологическим формам.

Высокое распространение диффузного нетоксического зоба (ДНЗ), многоузлового эндемического зоба (МУЗ) у взрослых отмечается в 
континентальной биозоне, субклинического гипотиреоза $(С Г)$ - в прибрежной биозоне. Это, по-видимому, связано с природными факторами, формирующими геохимическую ситуацию. В переходной биозоне антропогенный прессинг критической экологической ситуации способствует в большей степени возникновению ДНЗ и СГ, а в напряженной зоне - МУЗ.

У подростков отмечается высокая частота ДНЗ, значительно превышающая другие нозологические формы по всем биозонам и зонам экологической ситуации. В отличие от взрослых, наибольшая частота ДНЗ выявлена у подростков, проживающих в зоне с критической экологической ситуацией, особенно в переходной и прибрежной биоклиматических зонах.

Приведенные данные свидетельствуют о том, что под сильным неблагоприятным воздействием факторов среды обитания происходит срыв механизмов адаптации, проявляющийся в патологии тиреоидной системы. Обращают на себя внимание высокие уровни заболеваемости СГ в зонах с критической и напряженной экологической ситуациями.

Таким образом, проведенная эколого-гигиеническая оценка позволяет сделать следующие выводы:

- уровень тиреоидной патологии на территории Приморья наиболее высокий в районах, характеризующихся выраженным ЙД (северо-западные геохимические зоны), где структура заболеваний ЩЖ представлена преимущественно диффузным нетоксическим зобом. В прибрежных геохимических зонах, характеризующихся наибольшим содержанием йода, в структуре заболеваемости ЩЖ увеличиваются показатели АИЗ;

- возникновение ряда патологий ЩЖ у подростков и взрослых не всегда зависит от содержания йода в объектах ОС. На уровень заболеваемости среди данных групп населения влияют концентрации в почве мышьяка, свинца, кадмия и кобальта, обладающие выраженной токсичностью и струмогенностью. Высокие риски распространения заболеваний ЩЖ в 
зонах экологического напряжения региона связаны с дисбалансом микроэлементов в объектах $\mathrm{OC}$;

- заболевания ЩЖ, ассоциированные с ЙД, наряду с другими экологозависимыми заболеваниями могут рассматриваться как маркеры экологического неблагополучия ОС.

\section{Kiku P.F., Andryukov, B.G., Sitter N., Moreva V.G.}

\section{Ecological-hygienic assessment of the spread of iodine deficiency among the population of primorsky region}

The aim of the study was to determine the prevalence of thyroid diseases depending on ecological-hygienic situation. The study used descriptive statistical methods, ecological-hygienic examination. It is established that the level of thyroid pathology on the territory of Primorye is highest in areas characterized by severe iodine deficiency (North-West geochemical zones), where the structure of thyroid diseases are presented mainly diffuse non-toxic goiter. In coastal geochemical zones characterized by the greatest content of iodine in the structure of morbidity increase the indicators of autoimmune diseases.

Keywords: ecological-hygienic assessment of the prevalence of iodine deficiency diseases 


\section{Литература:}

1. Бузинов Р.В., Кику П.Ф., Унгуряну Т.Н., Ярыгина М.В., Гудков А.Б. От Поморья до Приморья: социально-гигиенические и экологические проблемы здоровья населения. Архангельск: Изд-во Северного государственного медицинского университета, 2016. 396 с.

2. Кику П.Ф., Гельцер Б.И. Экологические проблемы здоровья. Владивосток: Дальнаука. 2004. 228 с. 